\title{
RECONFIGURATION OF UNMANNED AIRCRAFT CONTROL SYSTEM
}

\author{
MARCIN ŻugAJ \\ Zakład Automatyki i Osprzętu Lotniczego, Wydział Mechaniczny Energetyki i Lotnictwa, Politechnika \\ Warszawska (Division of Automation and Aeronautical Systems, Faculty of Power and Aeronautical \\ Engineering, Warsaw University of Technology), ul. Nowowiejska 24, 00-665 Warsaw \\ zugaj@meil.pw.edu.pl
}

\begin{abstract}
Reliability of unmanned aircraft is a decisive factor for conducting air tasks in controlled airspace. One of the means used to improve unmanned aircraft reliability is reconfiguration of the control system, which will allow to maintain control over the aircraft despite occurring failures. The control system is reconfigured by using operational control surfaces, to compensate for failure consequences and to control the damaged aircraft. Development of effective reconfiguration algorithms involves utilization of a non-linear model of unmanned aircraft dynamics, in which deflection of each control surface can be controlled independently.

The paper presents a method for an unmanned aircraft control system reconfiguration utilizing a linear and nonlinear model of aerodynamic loads due to control. It presents reconfiguration algorithms, which differ with used models and with optimization criteria for deflections of failure-free control surfaces. Additionally it presents results of a benchmark of the developed algorithms, for various types of control system failures and control input.
\end{abstract}

Keywords: control, reconfiguration, unmanned aircraft.

\section{INTRODUCTION}

In recent years rapid development of unmanned aerial vehicles, both in military and in civilian applications has been seen. On the civil market a number solutions for UAV systems have appeared, which are intended for commercial and personal use. One of the key issues related to development of unmanned UAV systems is their safety, which currently is insufficient to allow air tasks to be performed in controlled airspaces [1]. Many research facilities around the world struggle to improve UAV systems safety to a level, that will permit their integration with air traffic control systems [2],[3].

Safety of an unmanned system depends on the reliability of its components. There are methods which allow to reduce effects of failures of individual system components. One of the key components 
of an UAV system, the reliability of which is essential for the aircraft usability in a controlled airspace, is the aircraft itself. Reliability of an unmanned aircraft depends on many factors, both external and internal ones, which include reliability of the control system [4]. In the event of a failure of the control system, one of the primary tasks set for control systems is to maintain controllability of the aircraft. The key method used to ensure control systems' reliability in manned aircraft is hardware redundancy, which reduces the probability of failures affecting the aircraft controllability. Some disadvantages of this method, which limit its applicability in UAVs, include; high cost of related solutions and higher complexity of the control system, its weight and occupied space [5]. Therefore, it seems natural to use control system reconfiguration methods [6],[7]. Reconfiguration of the control system is accomplished with numerical algorithms, which are designed to rely on still operational (failure-free) components of the control system in order to compensate for effects of a failure [8], which usually involves non-standard use of control surfaces. Control surfaces, in normal flights coupled in symmetrical pairs (e.g. elevators) or in asymmetrical pairs (ailerons) are then decoupled and controlled and deflected independently. Additionally, the reconfiguration attempts to utilize all functioning control surfaces, regardless of whether they would be deflected or not in the current phase of a normal (fault-less) flight. For example, flaps, which are normally used only during takeoff and landing, after control system reconfiguration may also be deflected in-flight. The role of the reconfiguration is not to restore the full functionality of the control system, but rather to ensure some degree of control, which would allow the aircraft to be safely brought back to its launch zone, to be landed in a random area or at least to be crashed in a controlled manner outside built-up areas. Effectiveness of the control system reconfiguration depends mainly on the aircraft dynamic properties and on the airframe configuration, which includes the number and types of control surfaces and the reconfiguration method and algorithm. There are many methods used for control system reconfiguration described in publications. These include: control allocation [9], sliding mode control - (SMC) [10] and multiple model control (MMC) [11]. In majority of cases, these methods are based on a linear aircraft dynamics model, which makes application of resulting reconfiguration algorithms in undefined flight conditions non-reliable. Additionally control system degradation due to a failure is also disregarded, which prevents real-life applications of the algorithm considering physical limitations of the system.

The paper presents a method for an unmanned aircraft control system reconfiguration using linear and nonlinear model of aerodynamic load due to control. It presents developed reconfiguration algorithms, which differ with used models and with optimization criteria for fault-free control surfaces deflections. Additionally it presents results of a benchmark of the developed algorithms for various types of control system failures and for various control input signals.

\section{UNMANNED AIRCRAFT CONTROL SYSTEM RECONFIGURATION ALGORITHMS}

\subsection{The general form of the unmanned aircraft dynamics model}

A small unmanned aircraft with a wingspan of $2.6 \mathrm{~m}$, total length of $1.25 \mathrm{~m}$, takeoff weight of up to $3 \mathrm{~kg}$ and maximum thrust of the power unit of $10 \mathrm{~N}$ was chosen for development of reconfiguration 
algorithms utilizing the control allocation method. Additionally the model was used to conduct simulation tests of developed algorithms. The aircraft was modeled as a rigid body with six degrees of freedom, with decoupled control surface actuation system, in which each control surface can be deflected independently. Additionally the following assumptions were made: mass-related parameters (weight, center of gravity location and inertial moments) not changing in flight, the aircraft will travel with a cruising speed of about $16 \mathrm{~m} / \mathrm{s}$ at the altitude of up to $30 \mathrm{~m}$, control surfaces will deflect without delays. For the spatial description of the aircraft motion the following Cartesian right-hand coordinate systems have been assumed (fig.1):

- inertial, stationary coordinate system $\mathrm{O}_{\mathrm{n}} \mathrm{x}_{\mathrm{n}} \mathrm{y}_{\mathrm{n}} \mathrm{z}_{\mathrm{n}}$, with the origin $\mathrm{O}_{\mathrm{n}}$ located at an arbitrary point on the earth surface, the direction of the $\mathrm{O}_{\mathrm{n}} \mathrm{z}_{\mathrm{n}}$ axis is coincident with the direction of the earth acceleration vector, the $\mathrm{O}_{\mathrm{n}} \mathrm{x}_{\mathrm{n}} \mathrm{y}_{\mathrm{n}}$ plane is tangent to the earth surface, the $\mathrm{O}_{\mathrm{n}} \mathrm{x}_{\mathrm{n}}$ axis is directed towards the north geographic pole with the $\mathrm{O}_{\mathrm{n}} \mathrm{y}_{\mathrm{n}}$ axis directed east,

- gravitational coordinate system $\mathrm{O}_{\mathrm{g}} \mathrm{x}_{\mathrm{g}} \mathrm{z}_{\mathrm{g}}$, related to a moving object, with the system's origin $\mathrm{O}_{\mathrm{g}}$ located at the aircraft's center of gravity, and the coordinate system is translated in parallel, relative to the $\mathrm{O}_{\mathrm{n}} \mathrm{x}_{\mathrm{n}} \mathrm{y}_{\mathrm{n}} \mathrm{z}_{\mathrm{n}}$ inertial system, and senses of both systems' axes are matching,

- the $\mathrm{O}_{b} \mathrm{x}_{\mathrm{b}} \mathrm{y}_{\mathrm{b}} \mathrm{zb}$ coordinate system is associated with the aircraft, the origin of the system $\mathrm{O}_{b}$ matches the origin of the gravitational system $\mathrm{O}_{\mathrm{g}}$, with the $\mathrm{O}_{\mathrm{b}} \mathrm{x}_{\mathrm{b}}$ axis located in the aircraft's plane of symmetry $\mathrm{O}_{b} \mathrm{x}_{b} \mathrm{z}_{b}$ and is directed towards the front of the aircraft's fuselage, the $\mathrm{O}_{b} \mathrm{z}_{b}$ axis is directed "down", with positive sense towards the aircraft's landing gear, and the $\mathrm{O}_{b} \mathrm{y}_{\mathrm{b}}$ axis completes the right-handed system and is directed right.

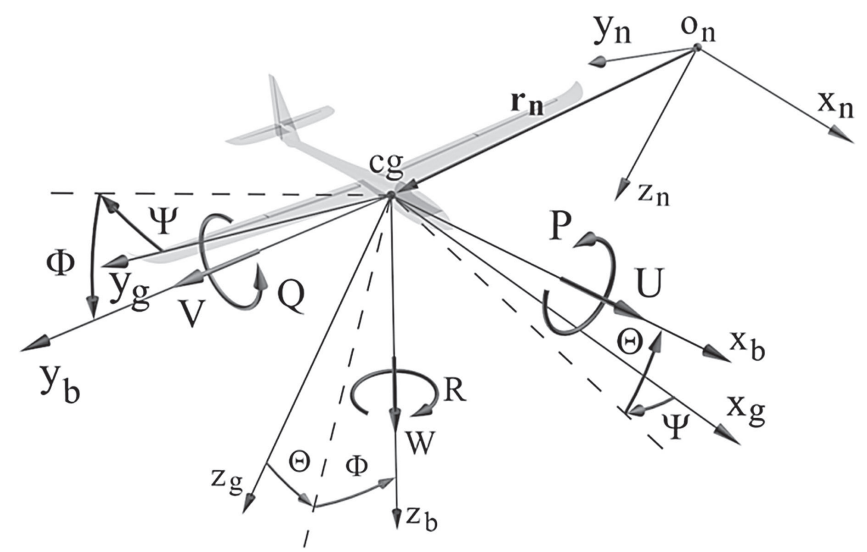

Fig. 1. Coordinate systems [Żugaj, 2016]

The aircraft motion equations were derived in the coordinate system associated with the aircraft $0_{b} x_{b} y_{b} z_{b}$. The aircraft state vector $\mathbf{x}$ contains linear velocity components $\mathbf{v}=\left[\begin{array}{lll}U & V & W\end{array}\right]$ ( $U$ - longitudinal speed, $V$ - lateral speed, $W$ - vertical speed) and angle $\boldsymbol{\omega}=\left[\begin{array}{lll}P & Q & R\end{array}\right]$ ( $P$ - roll angular velocity, $Q-$ pitch angular velocity, $R$ - yaw angular velocity) (fig.1.). The aircraft position and orientation are described by the $\mathbf{y}=\left[\begin{array}{llllll}x_{n} & y_{n} & z_{n} & \Phi & \Theta & \Psi\end{array}\right]^{\mathrm{T}}$ vector, where $x_{n}, y_{n}, z_{n}$ are aircraft's COG location vector components $\mathbf{r}_{\mathbf{n}}$ in the navigational coordinate system $O_{n} x_{n} y_{n} z_{n}, \Phi$ is the roll angle, $\Theta$ is the pitch angle and $\Psi$ is the aircraft yaw angle (fig.1). 
The relationships between the $\mathbf{x}=\left[\begin{array}{llllll}U & V & W & P & Q & R\end{array}\right]^{\mathrm{T}}$ state vector and the attitude and position vector $\mathbf{y}$ is described by the equation [12],[13]:

$$
\dot{\mathbf{y}}=\mathbf{T} \mathbf{x},
$$

where the $\mathbf{T}$ matrix has the form of:

$$
\mathbf{T}=\left[\begin{array}{cc}
\mathbf{T}_{\mathbf{V}} & \mathbf{0} \\
\mathbf{0} & \mathbf{T}_{\mathbf{\Omega}}
\end{array}\right],
$$

whereas [12],[13]:

$$
\begin{aligned}
& \mathbf{T}_{\mathbf{V}}=\left[\begin{array}{ccc}
\cos \Theta \cdot \cos \Psi & \sin \Theta \cdot \sin \Phi \cdot \cos \Psi-\cos \Phi \cdot \sin \Psi & \cos \Phi \cdot \sin \Theta \cdot \cos \Psi+\sin \Phi \cdot \sin \Psi \\
\cos \Theta \cdot \sin \Psi & \sin \Theta \cdot \sin \Phi \cdot \sin \Psi+\cos \Phi \cdot \cos \Psi & \cos \Phi \cdot \sin \Theta \cdot \sin \Psi-\sin \Phi \cdot \cos \Psi \\
-\sin \Theta & \sin \Phi \cdot \cos \Theta & \cos \Phi \cdot \cos \Theta
\end{array}\right], \\
& \mathbf{T}_{\mathbf{\Omega}}=\left[\begin{array}{ccc}
1 & \sin \Phi \cdot \tan \Theta & \cos \Phi \cdot \tan \Theta \\
0 & \cos \Phi & -\sin \Phi \\
0 & \sin \Phi \cdot \sec \Theta & \cos \Phi \cdot \sec \Theta
\end{array}\right]
\end{aligned}
$$

The general form of aircraft motion equations is described by [12],[13]:

$$
\mathbf{A} \dot{\mathbf{x}}+\mathbf{B x}=\mathbf{f}_{\mathrm{A}}+\mathbf{f}_{\mathrm{G}}+\mathbf{f}_{\mathrm{T}},
$$

where: $\mathbf{f}_{\mathbf{A}}$ is the aerodynamic loading vector, $\mathbf{f}_{\mathbf{G}}$ is gravity force loading vector, $\mathbf{f}_{\mathbf{T}}$ is the power unit thrust force loading vector, and:

$$
\mathbf{B}=\mathbf{\Omega} \mathbf{A},
$$

where matrices $\mathbf{A}$ and $\Omega$ have the following forms [12],[13]:

$$
\mathbf{A}=\left[\begin{array}{cccccc}
m & 0 & 0 & 0 & 0 & 0 \\
0 & m & 0 & 0 & 0 & 0 \\
0 & 0 & m & 0 & 0 & 0 \\
0 & 0 & 0 & I_{x} & 0 & -I_{x z} \\
0 & 0 & 0 & 0 & I_{y} & 0 \\
0 & 0 & 0 & -I_{x z} & 0 & I_{z}
\end{array}\right], \boldsymbol{\Omega}=\left[\begin{array}{cccccc}
0 & -R & Q & 0 & 0 & 0 \\
R & 0 & -P & 0 & 0 & 0 \\
-Q & P & 0 & 0 & 0 & 0 \\
0 & -W & V & 0 & -R & Q \\
W & 0 & -U & R & 0 & -P \\
-V & U & 0 & -Q & P & 0
\end{array}\right],
$$

whereas $m$ is the aircraft mass, $I_{x}, I_{y}, I_{z}$ are aircraft moments of inertia and $I_{x z}$ is the deviational moment of inertia.

The aerodynamic loading vector shall have the following form [14]:

$$
\mathbf{f}_{\mathbf{A}}(\mathbf{x}, \mathbf{y}, \boldsymbol{\delta})=\left[\mathbf{f}_{\mathbf{a}}(\mathbf{x}, \mathbf{y}, \boldsymbol{\delta}) \mathbf{m}_{\mathbf{a}}(\mathbf{x}, \mathbf{y}, \boldsymbol{\delta})\right]^{T},
$$

whereas the control vector has the following components [14]:

$$
\boldsymbol{\delta}=\left[\begin{array}{lllllll}
\delta_{A R} & \delta_{A L} & \delta_{E R} & \delta_{E L} & \delta_{F R} & \delta_{F L} & \delta_{R}
\end{array}\right]^{T},
$$

where: $\delta_{A R}$ - right aileron deflection angle, $\delta_{A L}-$ left aileron deflection angle, $\delta_{E R}$ - right elevator deflection angle, $\delta_{E L}$ - left elevator deflection angle, $\delta_{F R}$ - right flap deflection angle, $\delta_{F L}-$ left flap deflection angle, $\delta_{R}$ - rudder deflection angle. 
Aerodynamic force and moment vectors can be expressed as sums:

$$
\begin{aligned}
& \mathbf{f}_{\mathbf{a}}=\mathbf{F}_{\mathrm{AS}}+\mathbf{F}_{\mathrm{A} \boldsymbol{\Omega}}+\mathbf{F}_{\mathrm{AW}}+\mathbf{F}_{\mathrm{A} \delta}, \\
& \mathbf{m}_{\mathbf{a}}=\mathbf{M}_{\mathrm{AS}}+\mathbf{M}_{\mathrm{A} \boldsymbol{\Omega}}+\mathbf{M}_{\mathrm{AW}}+\mathbf{M}_{\mathbf{A} V}+\mathbf{M}_{\mathrm{A} \delta},
\end{aligned}
$$

where: $\mathbf{F}_{\mathbf{A S}}$ and $\mathbf{M}_{\mathrm{AS}}$ are vectors of static aerodynamic force and aerodynamic moment dependent on the angle of attack, glide angle, and the Mach number, $\mathbf{F}_{\mathbf{A} \boldsymbol{\Omega}}$ and $\mathbf{M}_{\mathbf{A} \boldsymbol{\Omega}}$ are vectors of the aerodynamic force and moment derivatives by linear speeds, $\mathbf{M}_{\mathbf{A} V}$ is a vector of aerodynamic moment derivatives by lateral speed, $\mathbf{F}_{\mathbf{A W}}$ and $\mathbf{M}_{\mathbf{A W}}$ are vectors of aerodynamic force and moment derivatives by vertical acceleration, and $\mathbf{F}_{\mathbf{A} \boldsymbol{\delta}} \mathbf{M}_{\mathbf{A} \boldsymbol{\delta}}$ are aerodynamic force and moment derivatives by control surfaces deflection angles.

\subsection{Reconfiguration method and algorithms}

The presented reconfiguration method has been developed for a small unmanned aircraft, with classic control actuation system consisting of one pair of ailerons, one pair of elevators, one pair of flaps and a single rudder. In the reconfiguration method adopted, it is assumed that each control surface can be deflected independently, which means that the system of control actuation uses seven independent control surfaces (fig. 2).

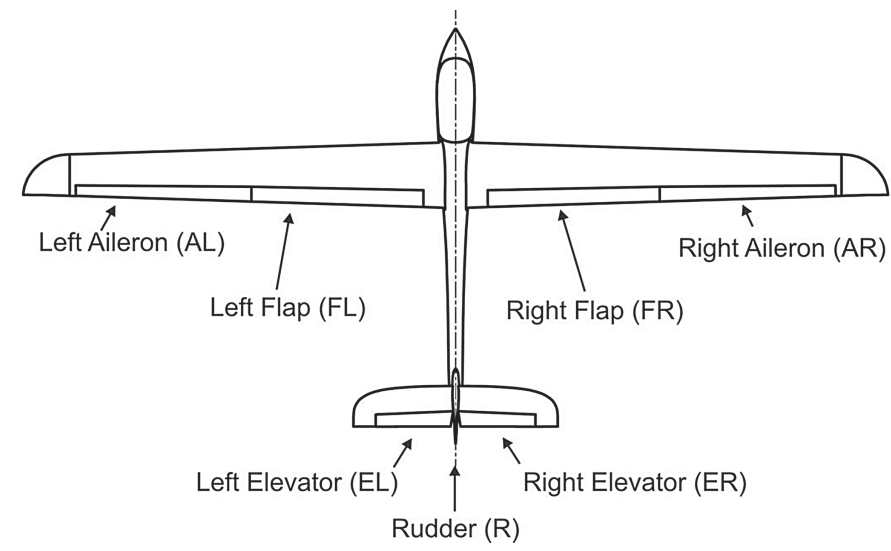

Fig. 2. Control System Configuration [Żugaj, 2014]

The developed reconfiguration method utilizes the control surface actuating system's failure information and a model of aerodynamic loadings generated by individual control surfaces. The method assumes that a fault is detected and is identified and that all necessary flight state variables are measured.

The general structure of the reconfiguration system is shown on fig. 3. A three-component vector $\boldsymbol{\delta}=\left[\begin{array}{lll}\delta_{L 0} & \delta_{H 0} & \delta_{R 0}\end{array}\right]^{T}$ is provided as the input, containing the values of aileron, rudder and elevator deflection angles set by the operator or by the automatic flight control system. This is the same control vector, which would be input in a fault-free state. Additionally the information is provided 
to the system indicating which control surface is locked and what is its current deflection angle $\mathbf{v}$. The reconfiguration algorithm calculates deflection angles of operational (failure-free) control surfaces $\boldsymbol{\delta}_{\boldsymbol{f}}$, creating a model of controllability derivatives. Deflection angles of operational control surfaces are determined in such a way so that the aerodynamic force and moment vectors generated by operational and faulty control actuators remain unchanged, i.e. have the same orientation, sense and norm. A problem defined in this way can be solved in multiple ways. The article presents four different variants of the algorithm, which implements this reconfiguration method. These variants differ in terms of used models of aerodynamic load from control, formulation of comparable vectors of control load and applied optimizations.

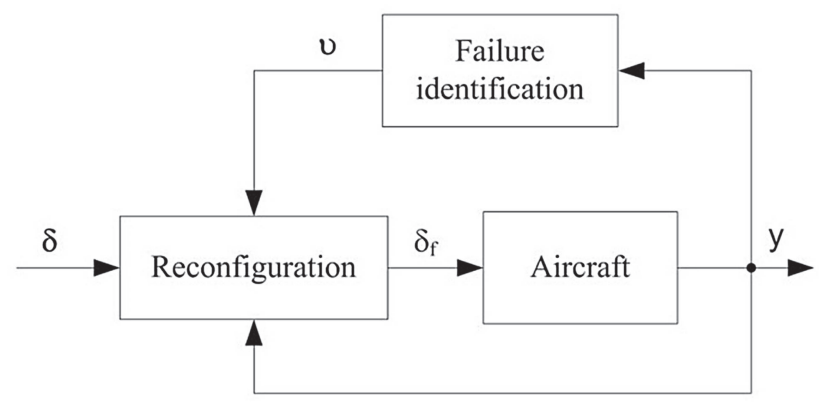

Fig. 3. The general diagram of the control system [Żugaj, 2016]

In the first variant of the reconfiguration algorithm (variant1) a linear model of aerodynamic loading due to control input has been used. This model omits the $\mathrm{x}$ component of the aerodynamic force assuming that their effects will be compensated by the altered thrust of the power unit.

The linearized equation (5) describing the aircraft dynamics in a fault-free state (further referred to as the reference model), reduced to five degrees of freedom (according to the above-mentioned assumption the force acting along the $\mathrm{x}$ axis is omitted), has the form:

$$
\dot{\mathbf{x}}_{\mathrm{m}}=\mathbf{A}_{\mathrm{m}} \mathbf{x}_{\mathrm{m}}+\mathbf{B}_{\mathrm{m}} \boldsymbol{\delta}
$$

where: $\boldsymbol{\delta}$ is the control input vector generated either by the operator or by the automatic control system.

According to the assumptions made, the state vector of the reference model shall have the following form:

$$
\mathbf{x}_{\mathbf{m}}=\left[\begin{array}{lllll}
V & W & P & Q & R
\end{array}\right]^{\mathrm{T}} .
$$

The model of the aircraft after a failure, can be expressed, as:

$$
\dot{\mathbf{x}}_{\mathbf{f}}=\mathbf{A}_{\mathbf{f}} \mathbf{x}_{\mathbf{f}}+\mathbf{B}_{\mathbf{f}} \boldsymbol{\delta}_{\mathbf{f}}+\mathbf{v},
$$

where: $\boldsymbol{v}$ is the vector of state vector disturbance caused by the failure, the $\mathbf{x}_{\mathbf{f}}$ state vector has the same components, as the $\mathbf{x}_{\mathrm{m}}$ vector, and the $\boldsymbol{\delta}_{\mathbf{f}}$ vector includes four deflection angles of operational control surfaces, according to the formula (9). 
The task of this reconfiguration algorithm is to ensure the same failed aircraft response to the control input, as it in case of a fully operational aircraft, that is:

$$
\mathbf{e}=\dot{\mathbf{x}}_{\mathbf{m}}-\dot{\mathbf{x}}_{\mathbf{f}}=0,
$$

which implies the following relation:

$$
A_{f} x_{f}+B_{f} \delta_{f}+v=A_{m} x_{m}+B_{m} \delta
$$

Assuming that faults in the control systems have little impact on dynamic properties of the aircraft [15] it may be assumed that:

$$
\mathbf{A}_{\mathrm{f}} \mathbf{x}_{\mathrm{f}} \approx \mathbf{A}_{\mathrm{m}} \mathbf{x}_{\mathrm{m}},
$$

therefore, the condition described by the equation (16) can be reduced to the following form:

$$
B_{f} \delta_{f}+v=B_{m} \delta,
$$

Hence we get the formula for the control vector of the damaged aircraft:

$$
\boldsymbol{\delta}_{\mathrm{f}}=\mathbf{B}_{\mathrm{f}}^{-1}\left(\mathbf{B}_{\mathrm{m}} \boldsymbol{\delta}-\boldsymbol{v}\right) \text {. }
$$

The above formula is an algebraic equation, which disregards physical constraints of the control system and which does not guarantee determination of an optimal control vector $\boldsymbol{\delta}_{\mathbf{f}}$. The solution obtained in this way is not always unambiguous, due to the fact that the system of equations may not have a solution (i.e. may be indefinite) or that the number of unknown variables may differ from the number of equations. In order to obtain a clear and at the same time an optimal solution, the algorithm has been modified using an optimization method, to determine the control vector of a failed aircraft. Minimization of operational control surface deflection angles has been assumed as the optimization criterion. Such formulated problem allows to achieve controllability of the failed aircraft comparable to a fully-operational one and limits the possibility of deflecting control surfaces past their permissible throws. The modified algorithm is identified as the variant 2 .

Similarly, as it is the case in the previous algorithm, a $\boldsymbol{\delta}_{\mathbf{f}}$ control vector is being sought for which the equation (18) is true. In this variant of the reconfiguration algorithm, this dependency constitutes an equation of the optimization algorithm constraints, with the goal function being the sum of squares of operational surfaces' deflection angles.

$$
f_{\delta_{f}}=\boldsymbol{\delta}_{\mathbf{f}, 1}{ }^{2}+\boldsymbol{\delta}_{\mathbf{f}, 2}{ }^{2}+\cdots+\boldsymbol{\delta}_{\mathbf{f}, i}{ }^{2}+\cdots .
$$

Thus the problem comes down to finding such deflection angles of operational control surfaces, for which the objective function (20) is minimized, while at the same time meeting the constraint equations (18):

$$
\min _{\delta_{\mathbf{f}}} f_{\delta_{f}} \text { dla }\left\{\mathbf{B}_{\mathbf{f}} \boldsymbol{\delta}_{\mathbf{f}}+\boldsymbol{v}-\mathbf{B}_{\mathbf{m}} \boldsymbol{\delta}=0\right\} .
$$

The constraint equation used in the second algorithm is time-invariant linear equation, which does not address the variability of control derivatives from the state vector. Due to this the response of the reference model will differ from the response of the actual aircraft. Therefore another 
algorithm (variant3) has been developed, in which the constraint equation has been formulated basing on a non-linear model of aerodynamic loads due to control input (equations 10 and 11). Similarly, as in the previous algorithm (variant2), such deflections of control surfaces are being sought, for which, under the set constraints, the goal function described by the equation (20) is minimized. Consequently the problem of determining minimal deflections of operational control surfaces can be expressed as:

$$
\min _{\delta_{\mathbf{f}}} f_{\delta_{f}} d l a\left\{\mathbf{f}_{\mathbf{A} \boldsymbol{\delta}}\left(\mathbf{x}, \mathbf{y}, \boldsymbol{\delta}_{\mathbf{f}}, \mathbf{v}\right)-\mathbf{f}_{\mathbf{A} \boldsymbol{\delta}}(\mathbf{x}, \mathbf{y}, \boldsymbol{\delta})=0\right\},
$$

whereas:

$$
\begin{aligned}
& \mathbf{f}_{\mathbf{A} \delta}(\mathbf{x}, \mathbf{y}, \boldsymbol{\delta})=\left[\begin{array}{ll}
\mathbf{F}_{\mathbf{A} \delta}^{\mathbf{y}, \mathbf{z}}(\mathbf{x}, \mathbf{y}, \boldsymbol{\delta}) & \mathbf{M}_{\mathbf{A} \delta}(\mathbf{x}, \mathbf{y}, \boldsymbol{\delta})
\end{array}\right]^{T}, \\
& \mathbf{f}_{\mathrm{A} \delta}\left(\mathbf{x}, \mathbf{y},\left\{\boldsymbol{\delta}_{\mathbf{f}}, \mathbf{v}\right\}\right)=\left[\begin{array}{lll}
\mathbf{F}_{\mathrm{A} \delta}^{\mathbf{y}, \mathbf{z}}\left(\mathbf{x}, \mathbf{y},\left\{\boldsymbol{\delta}_{\mathbf{f}}, \mathbf{v}\right\}\right) & \mathbf{M}_{\mathrm{A} \delta}\left(\mathbf{x}, \mathbf{y},\left\{\boldsymbol{\delta}_{\mathbf{f}}, \mathbf{v}\right\}\right)
\end{array}\right]^{T},
\end{aligned}
$$

where: $\mathbf{F}_{\mathbf{A} \delta}^{\mathbf{y}, \mathbf{z}}$ is a two-component vector of aerodynamic force due to control input, which contains only y-and z-axis components.

Use of non-linear constraint equations in the variant3 has significantly impacted the algorithm performance. The time of a single computation pass (iteration) has increased so much, that use of this algorithm in real-time applications becomes impossible. In order to reduce the computation time, the scope of the algorithm operation has been reduced by omitting ' $z$ ' component of the aerodynamic force due to control input from the constraints equation. It was assumed that changes of the ' $z$ ' component can be easily compensated by changes of the aircraft's angle of attack. In this way another reconfiguration algorithm (variant 4 ) has been created, which can be expressed, as:

$$
\min _{\delta_{\mathbf{f}}} f_{\delta_{f}} d l a\left\{\mathbf{f}_{\mathbf{A} \delta}\left(\mathbf{x}, \mathbf{y}, \boldsymbol{\delta}_{\mathbf{f}}, \mathbf{v}\right)-\mathbf{f}_{\mathbf{A} \delta}(\mathbf{x}, \mathbf{y}, \boldsymbol{\delta})=0\right\},
$$

whereas:

$$
\begin{aligned}
& \mathbf{f}_{\mathbf{A} \delta}(\mathbf{x}, \mathbf{y}, \boldsymbol{\delta})=\left[\begin{array}{lll}
F_{A \delta}^{y}(x, y, \delta) & \mathbf{M}_{\mathbf{A} \boldsymbol{\delta}}(\mathbf{x}, \mathbf{y}, \boldsymbol{\delta})
\end{array}\right]^{T}, \\
& \mathbf{f}_{\mathbf{A} \delta}\left(\mathbf{x}, \mathbf{y},\left\{\boldsymbol{\delta}_{\mathbf{f}}, \mathbf{v}\right\}\right)=\left[\begin{array}{ll}
F_{A \delta}^{y}\left(x, y,\left\{\delta_{f}, v\right\}\right) & \mathbf{M}_{\mathbf{A} \boldsymbol{\delta}}\left(\mathbf{x}, \mathbf{y},\left\{\boldsymbol{\delta}_{\mathbf{f}}, \boldsymbol{v}\right\}\right)
\end{array}\right]^{T},
\end{aligned}
$$

where: $F_{A \delta}^{y}$ is the lateral component of the vector of aerodynamic force due to control input.

\section{SIMULATION TESTS OF RECONFIGURATION ALGORITHMS FOR THE UNMANNED AIRCRAFT CONTROL SYSTEM}

The reconfiguration algorithm variants discussed above have been tested using the unmanned aircraft simulation model. Tests were aimed at checking the quality of reconfiguration, for each of the proposed methods. To evaluate the reconfiguration quality a criterion has been assumed involving comparison of attitude of a fully operational and failed aircraft after reconfiguration, flown under the same conditions and with the same configurations of faults and control signals. It was assumed 
that a reconfiguration is fully successful, if a change of the failed aircraft's attitude following the reconfiguration is near zero, and preferably if it is the same, as in a fully-operational plane. The larger the difference between the attitude of a failure-free plane and a failed plane, the lower is the effectiveness of the reconfiguration algorithm in question. During tests the differences in variability of other state variables have not been analyzed, as it was assumed that the change of the spatial orientation sufficiently well represents the aircraft controllability. Aircrafts are usually controlled by changing their attitude and changes of their flight path result from attitude. Control of the flight speed is an exception from this rule, as it significantly depends on the thrust force of the power unit. Therefore in case of this state variable, it was assumed that the aircraft's power unit is operational and that it produces sufficient thrust to attain the set flight speed. It shall be noted that the reconfiguration algorithm is not required to ensure the same controllability of a damaged aircraft as the controllability of a fully-operational aircraft. In case of complex failures (involving several control surfaces at the same time), such functionality of the reconfiguration system may render completely unattainable. A benefit of the control system reconfiguration is the ability to improve the aircraft's controllability as much, as allowed by the control system design, by the nature of the failure and by the effectiveness of the reconfiguration method.

During tests various configurations of failures and control signals were simulated. Then plots of fully-operational and failed aircraft attitude (orientation) changes were compared for each of the reconfiguration algorithm variants developed. The following failure configurations were assumed for tests:

A. Right aileron blocking in deflected by 5 degrees position,

B. Left elevator blocking in deflected by 5 degrees position,

C. Rudder blocking in deflected by 3 degrees position,

D. Simultaneous blocking of the right aileron (deflected by 5 degrees) and of the left elevator (deflected by 5 degrees),

E. Simultaneous blocking of the right aileron (deflected by 5 degrees) and of the rudder (deflected by 3 degrees),

F. Simultaneous blocking of the left elevator (deflected by 5 degrees) and of the rudder (deflected by 3 degrees).

Configurations of the control input signals $\boldsymbol{\delta}$ simulated during tests were the following:

1. Doubled rectangular pulse signal (“doubled") (fig. 4) for roll (ailerons),

2. Multiple rectangular pulses signal ("3-2-1-1") (fig. 4) for pitch (elevator),

3. "Doubled" rectangular pulse signal (fig. 4) for yaw (rudder).

4. Concurrent "doubled" signals for roll (ailerons) and "3-2-1-1" for pitch (elevator),

5. Concurrent "doubled" signals for roll (ailerons) and "doubled" signal for yaw (rudder),

6. Concurrent "doubled" signals for yaw and "3-2-1-1" for pitch (elevator),

7. Concurrent "doubled" signals for roll (ailerons) and yaw (rudder) and "3-2-1-1" for pitch (elevator).

The waveforms of the control input signals used in the paper are standard signals used in testing of dynamic properties and in identification of aircraft flight dynamics [16],[17]. These signals are simple to implement and cause predictable response of the aircraft to control input. 


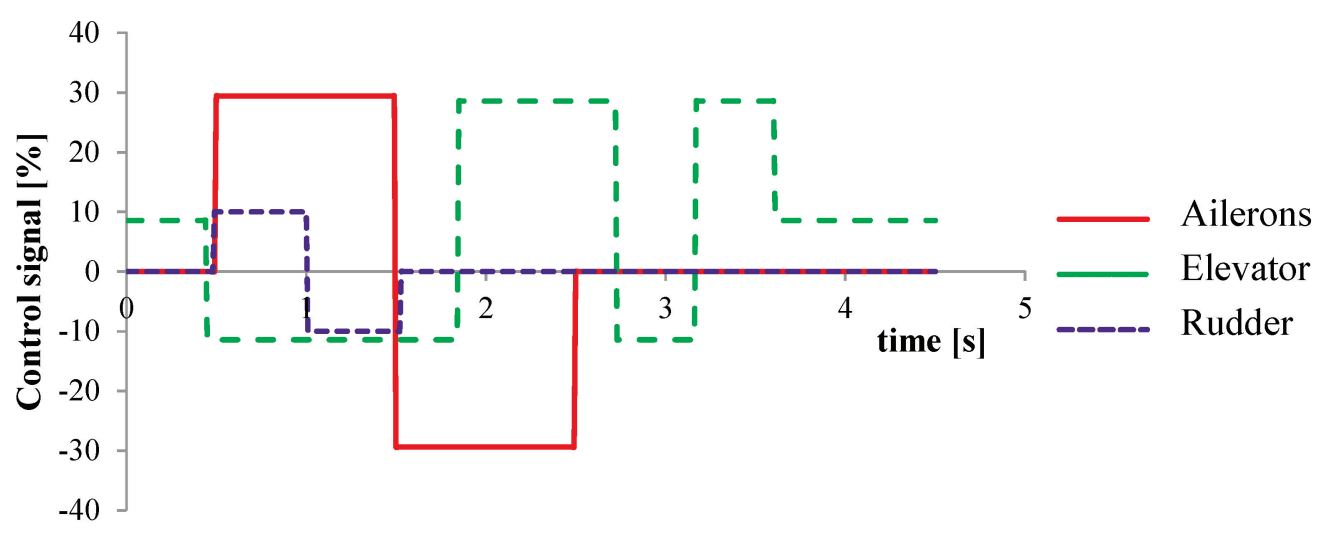

Fig. 4. Waveforms of the control input signals $\delta$ expressed as percentages of their maximum values [Żugaj, 2016]

During tests, simulations of all failure combinations (A to F) and of all control signals (1 to 7) were performed. Next, waveforms of failed aircraft attitude changes without reconfiguration and after reconfiguration (for all variants of the reconfiguration algorithm) have been compared with fully-operational aircraft attitude waveforms for the same control input. For comparison, an integrated square quality index in the following form has been used:

$$
I_{R}=\int_{0}^{t k}\left(x_{\text {bez_awarii }}-x_{z_{-} \text {awaria }}\right)^{2} d t
$$

where: $x$ is the signal being compared, and $t_{k}$ is the end of the simulation time.

The lower the difference between the response of a failure-free plane and a failed plane, the lower is the quality index value.

Obtained results of the comparison between the operational and a failed aircraft have been subjected to statistical analysis in order to determine the mean value and the distribution of the quality index for all combinations of the failures and control signals (42 cases in total). In order to facilitate the analysis of such considerable amounts of data, results have been grouped into three categories:

I. a single failure (A-C) and a single control input (1-3),

II. a dual failure (A-F) and a single control input (1-3),

III. a single failure (A-C) and two or three control inputs (4-7).

Arithmetic mean and standard deviation values of the quality index for the first category of results are shown in the table 1 . Mean and standard deviation values for a failed aircraft without reconfiguration are significantly higher than after reconfiguration. Differences between mean values for all variants of the reconfiguration algorithm are not high. The best reconfiguration quality has been obtained for the third and fourth variant. It can not be clearly stated which of the two variants is the best. In the fourth variant the lowest mean value has been obtained. In the third variant the mean value is somewhat higher, but the distribution is narrower. Detailed analyses of statistics have shown that all variants of algorithms struggled the most with aileron failure reconfiguration. For this type of failure, the highest values of the quality index have been achieved. This is caused by the fact that 
an aileron failure generates significant yawing moment, which can only be compensated by rudder deflection. Deflection of the rudder however creates additional rolling moment and a lateral force, which is difficult to compensate, as additional control surfaces may only generate lateral forces with significantly lower values than the force generated by the rudder.

Figures 5 to 7 show sample plots of attitude angle changes of a failure-free aircraft and of a failed aircraft, with and without the reconfiguration, for the elevator failure (failures B) and for the "3-2-1-1" signal for roll (signal 2). One can clearly see that the damaged aircraft without reconfiguration is unable to achieve the specified pitch change. Additionally roll and yaw of the aircraft continue to rise. Analysis of all simulation cases has shown that attitude errors without reconfiguration may even reach 70 degrees.

Table 1. Statistics of the quality index for the 1st category of results [Żugaj, 2016]

\begin{tabular}{lcc}
\hline & Mean & Standard deviation \\
\hline No reconf. & $1,682.98$ & $2,013.71$ \\
\hline Variant 1 & 65.57 & 141.66 \\
Variant 2 & 58.60 & 144.17 \\
Variant 3 & 44.01 & 103.93 \\
Variant 4 & 42.87 & 127.23 \\
\hline
\end{tabular}

Table 2. Statistics of the quality index for the 2 nd category of results [Żugaj, 2016]

\begin{tabular}{lcc}
\hline & Mean & Standard deviation \\
\hline No reconf. & $3,571.33$ & $3,943.68$ \\
\hline Variant 1 & $3,323.76$ & $8,837.20$ \\
Variant 2 & $5,969.33$ & $11,555.18$ \\
\hline Variant 3 & $4,458.35$ & $7,754.41$ \\
Variant 4 & $8,49.67$ & $1,816.94$ \\
\hline
\end{tabular}

In case of the second category of results, variant 4 of the reconfiguration algorithm (table 2) performed the best. Other algorithms managed to the problem slightly better than the system without reconfiguration. It can be clearly seen that variants 2 and 3 performed worse than in case of no reconfiguration. Concurrent failure of the elevator and the rudder (failure F) turned out to be the most difficult for reconfiguration in case of all variants of the algorithm. In most cases, in this configuration the aircraft lost controllability, which in combination with blocked control surfaces in a deflected position caused uncontrolled rotation in the roll and yaw channel. Large values of the quality index for this combination of the failure depend mostly on the time after which the aircraft was losing controllability. As detailed analyses shown, use of some variants of the algorithm caused destabilization of the aircraft flight path earlier than in case of no reconfiguration. In case of other combinations of failures, all variants of the reconfiguration algorithm achieved better quality index values than in case of no reconfiguration. 


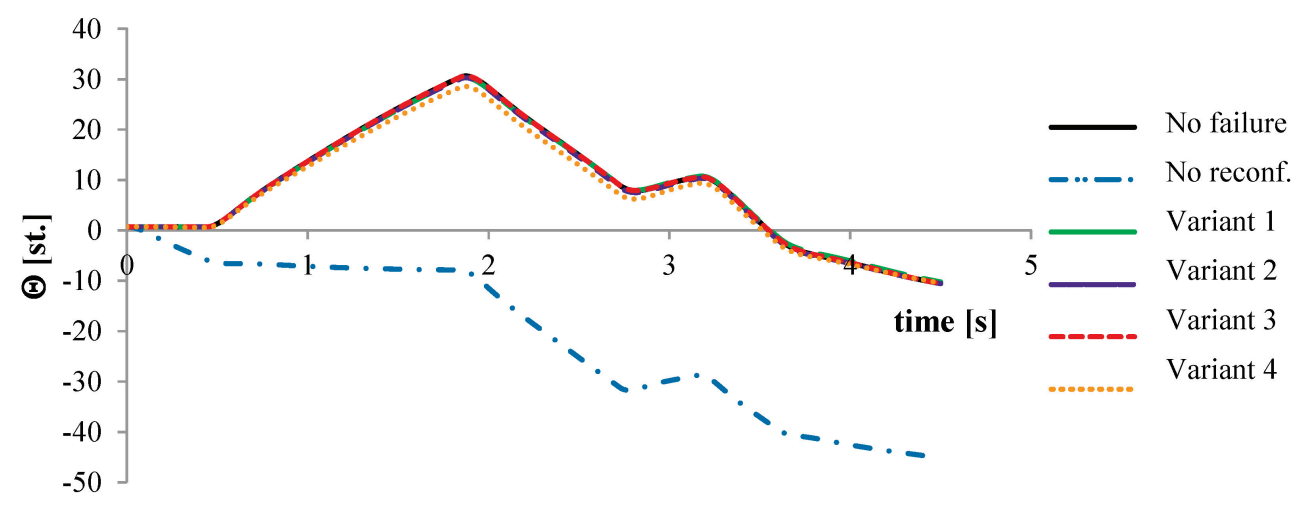

Fig. 5. Changes of the pitch angle for the $1^{\text {st }}$ category of results [Żugaj, 2016]

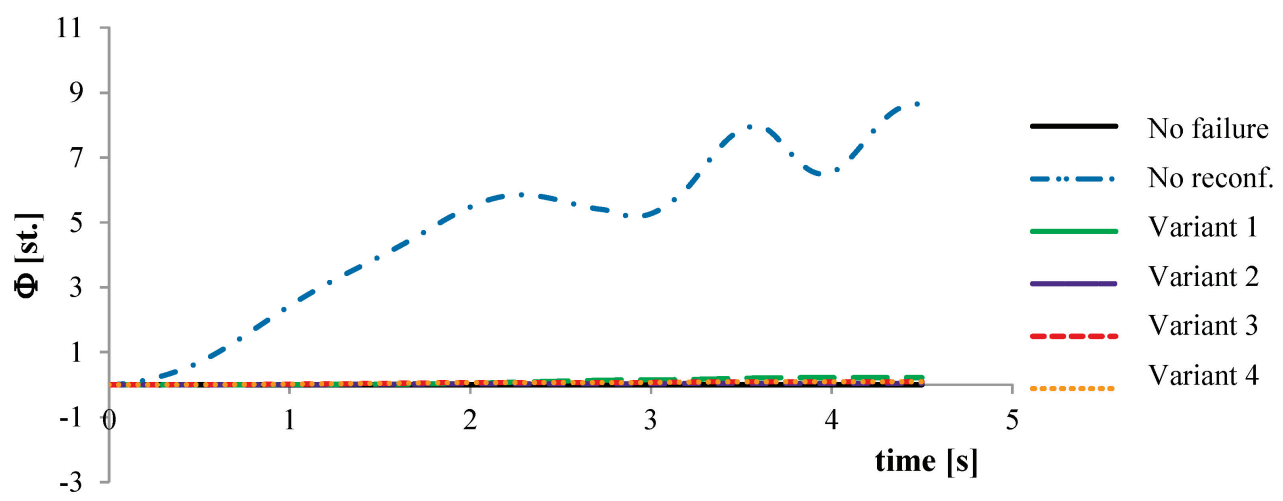

Fig. 6. Changes of the roll angle for the $1^{\text {st }}$ category of results [Żugaj, 2016]

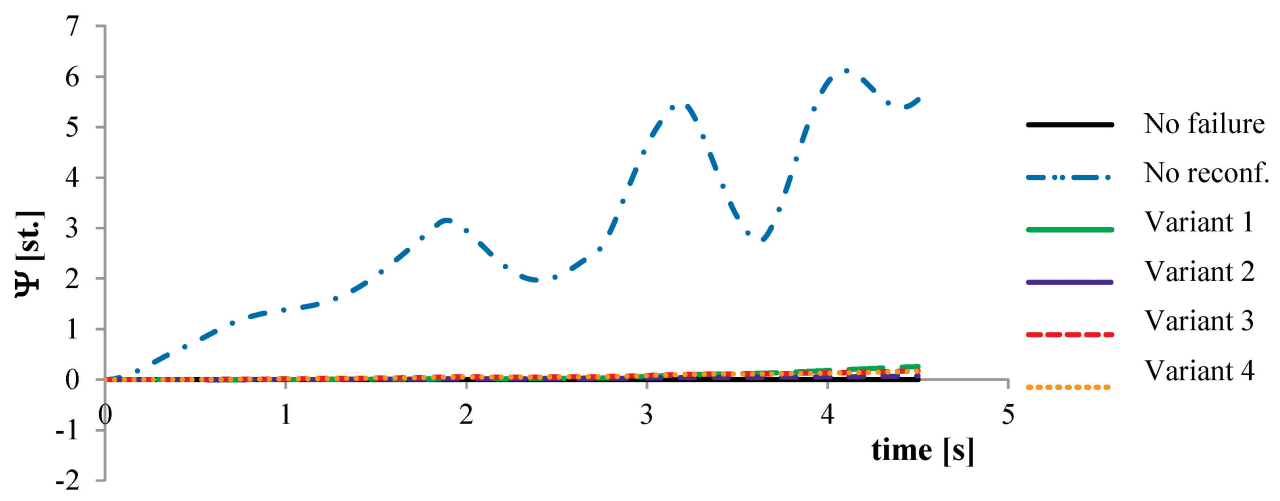

Fig. 7. Changes of the yaw angle for the $1^{\text {st }}$ category of results [Żugaj, 2016]

Figures 8 to 10, for example, show a comparison of aircraft attitude angle variations for a failure of an aileron and elevator (failure D) and for the "3-2-1-1" signal in the pitch channel (signal 2). This is the case of a failure, for which the reconfiguration turned out to be successful. However 
one can notice that, compared to a single failure (figures 5 to 7), in this case the quality of the reconfiguration is somewhat worse. A change of a failed aircraft pitch despite similar behavior differs somewhat from the change of a failure-free aircraft pitch. Also a change in the failed aircraft's roll and yaw can be clearly seen.

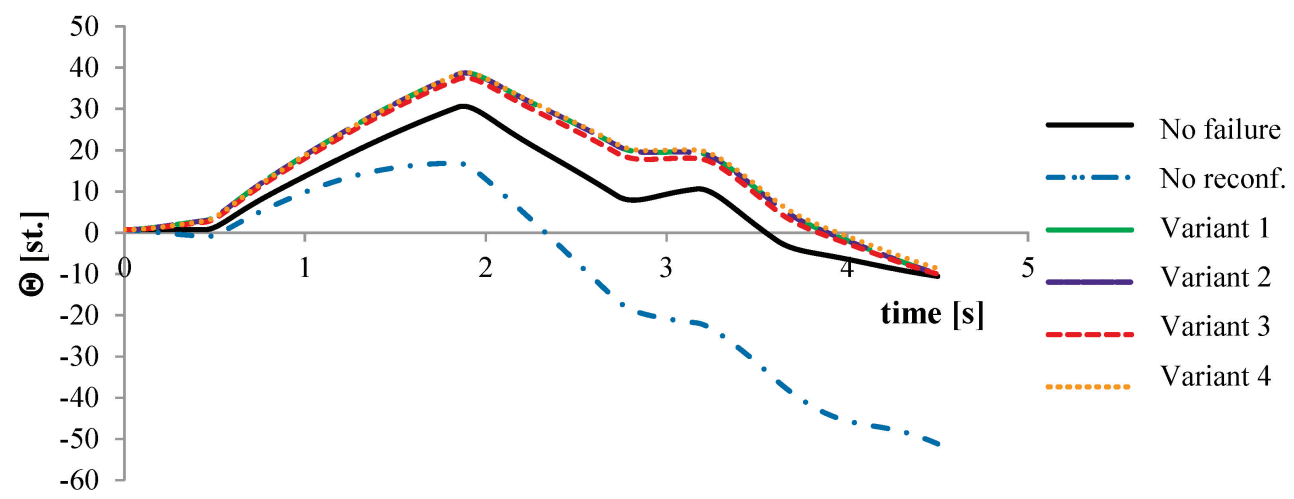

Fig. 8. Changes of the pitch angle for the $2^{\text {nd }}$ category of results [Żugaj, 2016]

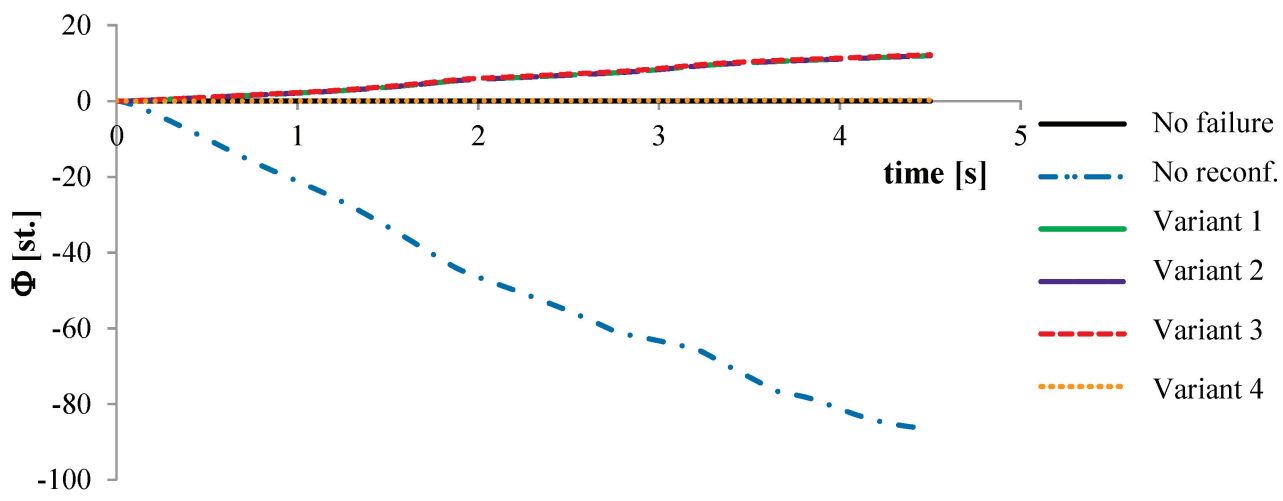

Fig. 9. Changes of the roll angle for the $2^{\text {nd }}$ category of results [Żugaj, 2016]

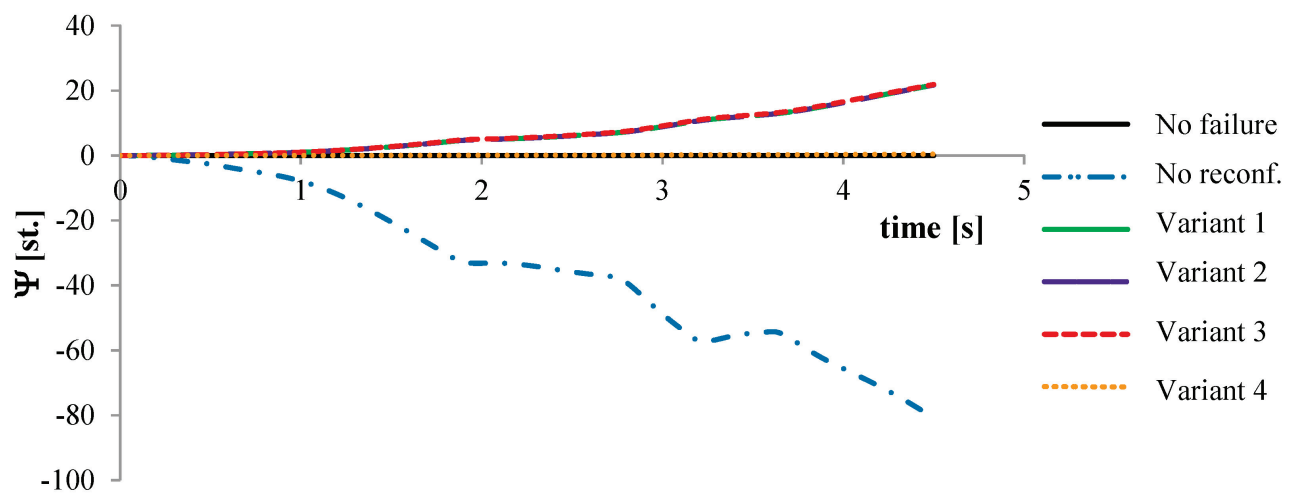

Fig. 10. Changes of the Yaw angle for the $2^{\text {nd }}$ category of results [Żugaj, 2016] 
Results for the last, third category are presented in table 3. It is apparent that all variants of the algorithm scored by a magnitude better than in no-reconfiguration case. The algorithm in variant 3 handled a single failure with concurrent two or three control input signals (signal 7) the best. Similarly, as in the first category, also in this case aileron failure turned out to be the most difficult for reconfiguration.

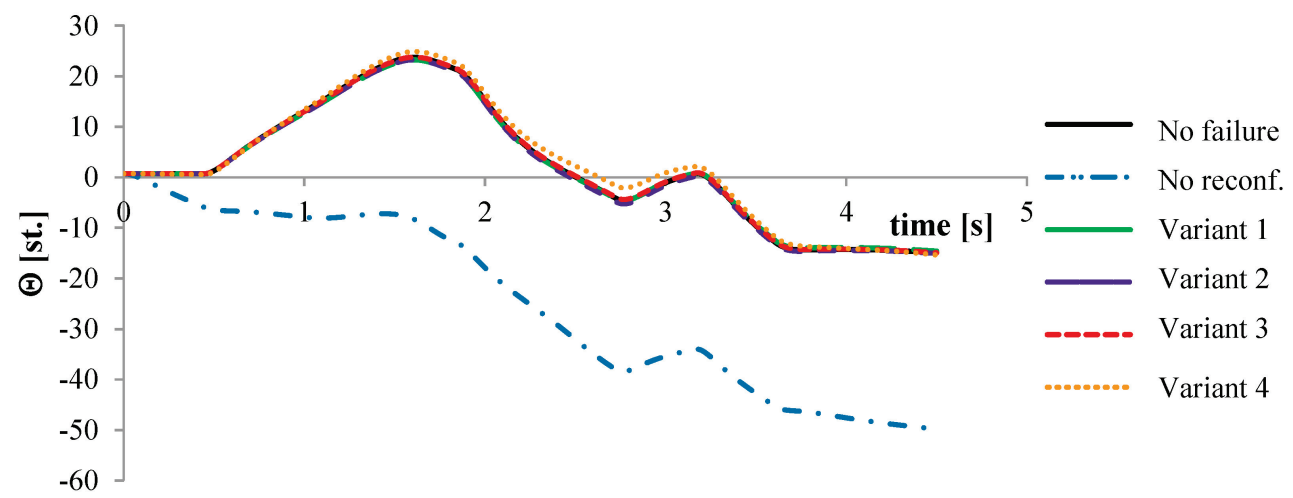

Fig. 11. Changes of the pitch angle for the $3^{\text {rd }}$ category of results [Żugaj, 2016]

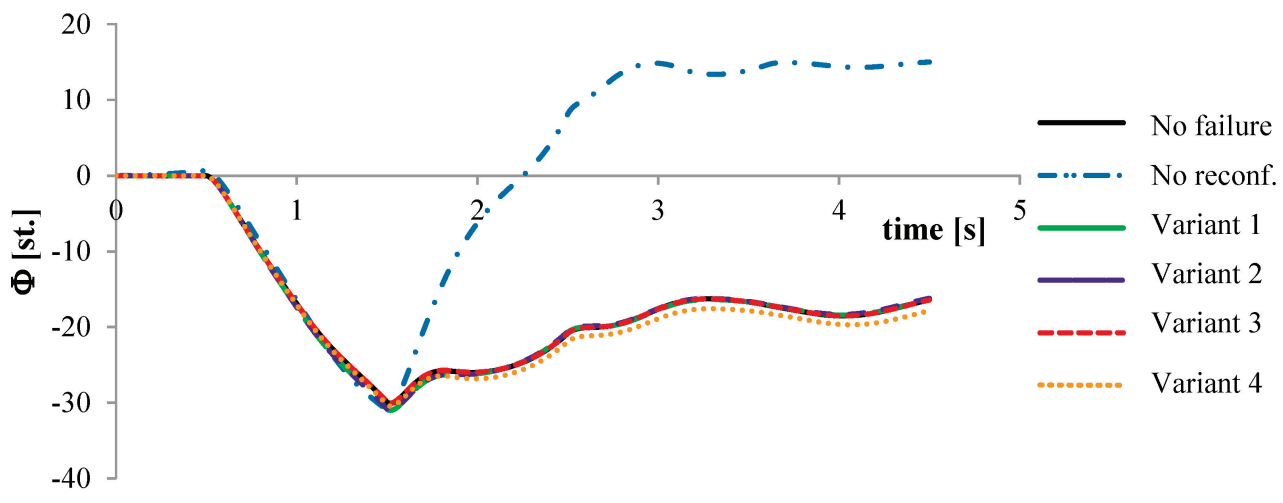

Fig.12. Changes of the roll angle for the $3^{\text {rd }}$ category of results [Żugaj, 2016]

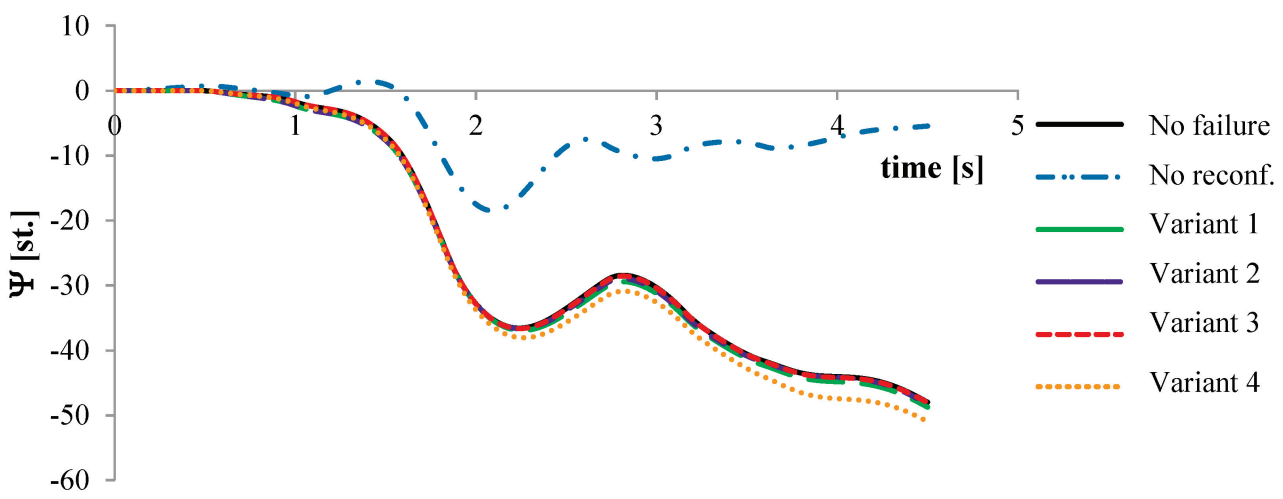

Fig. 13. Changes of the Yaw angle for the $3^{\text {rd }}$ category of results [Żugaj, 2016] 
Table 3. Statistics of the quality index for the $3^{\text {rd }}$ category of results [Żugaj, 2016]

\begin{tabular}{lcc}
\hline & Mean & Standard deviation \\
\hline No reconf. & $1,721.91$ & $1,779.44$ \\
\hline Variant 1 & 128.53 & 230.43 \\
Variant 2 & 120.04 & 235.25 \\
Variant 3 & 89.94 & 125.77 \\
Variant 4 & 160.12 & 263.03 \\
\hline
\end{tabular}

Figures 11 to 13 show sample waveforms of attitude angles for the elevator failure (failure B) and concurrent control input of all signals (signal 7). Results show that reconfiguration significantly improves the aircraft control quality. Similarly as in the first category, also in this case difference of the failed, non-reconfigured aircraft attitude angles compared to a failure-free aircraft reached up to several dozens degrees.

Conducted simulations of various failure configurations and control inputs have shown that the proposed reconfiguration method permits compensation of control system failure effects. Control signals generated by the reconfiguration system did fit within permissible deflection ranges of control surfaces. In case of individual failures, aileron failure turned out to be the most difficult for reconfiguration due to its generated yawing moment and lack of control system redundancy for yawing moment control. Even that in case of this failure the quality indices are the least favorable, the aircraft remains fully controllable after its reconfiguration. The situation is significantly worse in case of dual failure reconfiguration. In most cases the quality indices are significantly higher and aircraft behavior following reconfiguration differs slightly from behavior of a failure-free aircraft. In case of simultaneous failure of elevator and rudder, the aircraft loses controllability without reconfiguration as well as in case of the majority of reconfiguration algorithm variants.

\section{CONCLUSIONS}

The paper presents a method for unmanned aircraft control system reconfiguration. It also presents the general form of a non-linear model of aircraft with decoupled control surfaces, which has been used to develop four variants of reconfiguration algorithm and for simulation testing. Algorithm variants differed with used optimization methods and with use of either linear or non-linear model of aerodynamic load due to control input. It also presents results from analyses of simulation studies performed for various failure configurations and for various control signals. Results have shown that the developed reconfiguration algorithm, performs very good in case of a single control surface failure. In case when there are two concurrent failures occurring, in most cases reconfiguration algorithms ensure reasonably good control over the aircraft. The exception is the concurrent failure of the elevator and the rudder, in case of which the aircraft can not be controlled. This results from the fact that the control system redundancy is too low for that type of failure to be successfully reconfigured and addressed. It seems that the only possible solution allowing to compensate for such failures would be introduction of design modifications involving an increase of the number of available control 
surfaces. One shall keep in mind that the reconfiguration quality assessment method used in the paper is only intended for comparison of various reconfiguration algorithm variants' effectiveness for purposes of their optimization. Therefore this assessment may not be used as a basis for evaluating usability of the method, as such. In case of a complex failure of the control system, even if the efficiency of the reconfiguration algorithm is low, its usability may be invaluable, if only it could be able to ensure reasonably correct control over the aircraft. The analysis of the results has shown that the best reconfiguration results are obtained when the reconfiguration algorithm is based on a non-linear aircraft model. However algorithms using linear models require significantly lower computing power, which gives more opportunities for their practical applications.

\section{REFERENCES}

[1] Goetzendorf-Grabowski, T., Frydrychewicz, A., Goraj, Z., et al., 2006, "MALE UAV design of an increased reliability level," Aircraft Engineering and Aerospace Technology: An International Journal, vol. 78, No 3, pp. 226-235.

[2] Lin, X., Fulton, N., and Horn, M., 2014, ,Quantification of high level safety criteria for civil unmanned aircraft systems;" Proceedings of IEEE Aerospace Conference, Big Sky, March 1-8, pp. 1-13.

[3] Loh, R., Bian, Y., and Roe, T., 2009, „UAVs in civil airspace: Safety requirements;” IEEE Aerospace and Electronic Systems Magazine, 24, January, pp. 5-17.

[4] Goraj, Z., 2014, "A specialized UAV for surveillance in windy, turbulent environment of the Antarctic coast," Proceedings of the 29th Congress of the International Council of the Aeronautical Sciences Vol I-VI, Curran Associates, Inc, pp. 1-13.

[5] Steinberg, M., 2005, „A historical overview of research in reconfigurable flight control;" Proceedings of the Institution of Mechanical Engineers, Part G: Journal of Aerospace Engineering, 219, April, pp. 263-275.

[6] Kozak, V., Shevchuk, D., Vovk, V., and Levchenko, M., 2014, „Automation of aircraft control Rreconfiguration in flight special situations;" Proceedings of IEEE 3rd International Conference on Methods and Systems of Navigation and Motion Control, Kiev, October 14-17, pp. 14-17, October 2014.

[7] Yang, Z., Hua, S., Hongzhuan, Q., and Chengrui, L., 2010, „Control reconfigurability of nonlinear system based on control redundancy;" 10th IEEE International Conference on Industrial Informatics (INDIN), Beijing, July 25-27, pp. 815-820.

[8] Burcham, B., 1997, „Landing safely when flight controls fail;” Aerospace America, pp. 20-23.

[9] Naskar, A., Patra, S., and Sen, S., 2015, „Reconfigurable Direct Allocation for Multiple Actuator Failures;" IEEE Transactions on Control Systems Technology, 1(23), January, pp. 397-405.

[10] Xiao-hui, Q., and Hong-tao, Z., 2011, „The Design od Adaptive Sliding Mode Control Law on Reconfigurable Flight Control System;" International Conference on Electronics, Communications and Control (ICECC), Ningbo, September 9-11, pp. 532-536.

[11] Fekri, S., Gu, D., and Postlethwaite, I., 2009, „Lateral Imbalance Detection on a UAV Based on Multiple Models;" Joint 48th IEEE Conference on Decision and Control and 28th Chinese Control Conference, Shanghai, December 16-18, pp. 8488-8493. 
[12] Nizioł, J., 2005, Dynamika układów mechanicznych (Dynamics of mechanical systems), Komitet Mechaniki PAN (Mechanics Committee of the Polish Academy of Sciences). Instytut Podstawowych Problemów Techniki Polskiej Akademii Nauk (Institute of Fundamental Technological Problems of the Polish Academy of Sciences), Warsaw.

[13] Goraj, Z., 2014, "Flight dynamics models used in different national and internationals projects," Aircraft Engineering and Aerospace Technology, Volume: 86 Issue: 3.

[14] Zugaj, M., and Narkiewicz, J., 2009, „Autopilot for reconfigurable flight control system;” ASCE Journal of Aerospace Engineering, 22, January, pp. 78-84.

[15] Żugaj, M., Godłoża, D., 2016, „Analiza właściwości dynamicznych samolotu bezzałogowego w stanie awarii systemu sterowania;" (Analysis of dynamic properties of an unmanned aircraft in a failure state). Mechanika w Lotnictwie (Mechanics in Aeronautics) ML-XVII, vol. 2, Warszawa, pp. 275-286.

[16] Jategaonkar, R., V., 2006, Flight Vehicle System Identification, A Time Domain Methodology, American Institute of Aeronautics and Astronautics, Reston, Virginia.

[17] Yechout, T., R., 2003, Introduction to Aircraft Flight Mechanics: Performance, Static Stability, Dynamic Stability, and Classical Feedback Control, American Institute of Aeronautics and Astronautics, Reston, Virginia.

\section{REKONFIGURACJA UKLADU STEROWANIA SAMOLOTU BEZZALOGOWEGO}

\section{Streszczenie}

Niezawodność samolotów bezzałogowych jest czynnikiem decydującym o możliwości wykonywania zadań lotniczych w kontrolowanej przestrzeni powietrznej. Jedną z metod wykorzystywanych do poprawy niezawodności samolotów bezzałogowych jest rekonfiguracja układu sterowania, która umożliwia sterowanie samolotem pomimo powstałej awarii. Rekonfiguracja systemu sterowania polega na wykorzystaniu sprawnych powierzchni sterowych do kompensacji skutków awarii oraz sterowania uszkodzonym samolotem. Opracowanie efektywnych algorytmów rekonfiguracji wymaga wykorzystania nieliniowego modelu dynamiki samolotu bezzałogowego, w którym możliwe jest niezależne sterowanie wychyleniem każdej powierzchni sterowej.

W pracy przedstawiono metodę rekonfiguracji układu sterowania samolotu bezzałogowego w której, wykorzystano liniowy i nieliniowy model obciążeń aerodynamicznych od sterowania. Przedstawiono algorytmy rekonfiguracji, które różnią się użytymi modelami oraz kryteriami optymalizacji wychyleń sprawnych powierzchni sterowych. Ponadto przedstawiono wyniki porównania opracowanych algorytmów dla różnych konfiguracji awarii systemu sterowania oraz zadanych sygnałów sterujących. Słowa kluczowe: sterowanie, rekonfiguracja, samoloty bezzałogowe

"The paper was drafted within the scope of the PBS2/B6/19/2013 project, financed by the Narodowe Centrum Badań i Rozwoju (National Centre for Research and Development) between 2013 and 2016". 